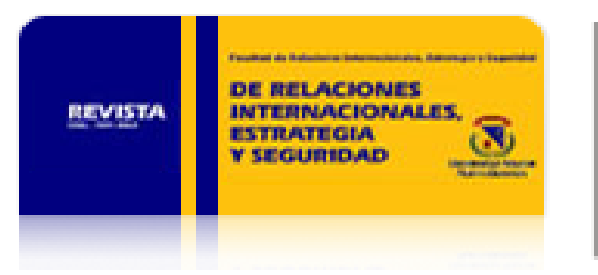

Revista de Relaciones Internacionales, Estrategia y Seguridad

ISSN: 1909-3063

cinuv.relinternal@unimilitar.edu.co

Universidad Militar Nueva Granada

Colombia

Ripoll, Alejandra; Lara, Ana María

LAS MIGRACIONES INTRACOMUNITARIAS EN LA REGIÓN ANDINA

Revista de Relaciones Internacionales, Estrategia y Seguridad, vol. 3, núm. 2, julio-diciembre, 2008,

pp. 93-112

Universidad Militar Nueva Granada

Bogotá, Colombia

Disponible en: http://www.redalyc.org/articulo.oa?id=92712967005

- Cómo citar el artículo

- Número completo

- Más información del artículo

- Página de la revista en redalyc.org

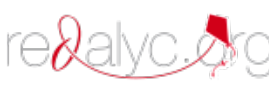

Sistema de Información Científica

Red de Revistas Científicas de América Latina, el Caribe, España y Portugal

Proyecto académico sin fines de lucro, desarrollado bajo la iniciativa de acceso abierto 
rev.relac.int.estrateg.segur.3(2):93-112,2008

\title{
LAS MIGRACIONES INTRACOMUNITARIAS EN LA REGIÓN ANDINA*
}

\author{
Alejandra Ripoll** y Ana María Lara***
}

\section{RESUMEN}

La migración intracomunitaria en la región andina, es un tema de suma importancia en las agendas internacionales de los países andinos, debido al incremento significativo de la población migrante. La gestión migratoria debe partir del diálogo y la cooperación entre países de recepción y los de origen, por esta razón es necesario introducir en espacios

\footnotetext{
* Este documento es producto de una investigación sobre documentos de los acuerdos y resoluciones existentes en la Región Andina, en materia de migraciones, para que sirva de insumo para la Ley Nacional de Migraciones de Colombia. Apartes de este documento reposan en el Ministerio de Relaciones Exteriores de Colombia,. Agradecemos a Camilo Vallejo y Néstor Orduz por las ideas que aportaron en la elaboración de este ensayo.

${ }^{* *}$ Magistra en Relaciones Internacionales, Pontificia Universidad Javeriana, editora de la revista de Relaciones Internacionales, Estrategia y Seguridad de la Universidad Militar Nueva Granada. Alejandra.ripoll@umng.edu.co, aripoll@javeriana.edu.co

*** Profesional en Finanzas y relaciones Internacionales, Universidad Externado de Colombia. Consultora externa del Proyecto MIGRANDINA de la Oficina Internacional del Trabajo - OIT-. amlarasalinas@hotmail.com
} 
multilaterales la necesidad de un mayor nivel de responsabilidad recíproca en la gobernanza y la relación de los países con la migración.

Una de las grandes dificultades que se presenta para lograrlo, es la falta de identidad en la región para tratar el problema de las migraciones en la medida que limita la libre circulación de personas.

Palabras clave: migraciones, seguridad, securitización, acuerdos interestatales

\section{ABSTRACT}

The intracommunitarian migration in the Andean region is a subject of extreme importance in the international agenda of the Andean countries, due to the significant increase of the migrant population. The migratory management must start with dialogue and cooperation between the receiving and the countries of origin; therefore it's necessary to introduce in multilateral spaces the necessity of a greater level of reciprocal responsibility in the management and relations of the countries regarding migration.

One of the major difficulties to achieve it is the lack of identity in the region to deal with the migration problem, since it limits the free movement of people.

Key words: migrations, security, securitization, interstate agreements

\section{INTRODUCCIÓN}

La región Andina se ha caracterizado por su heterogeneidad a pesar de compartir una complexión histórica y cultural similar. A lo largo de sus relaciones, ha demostrado serias contradicciones y pocas intenciones de universalizar ciertas normas que faciliten el intercambio social y económico.

En este marco, la migración dentro de la Región se ha convertido en un tema espinoso sobre todo, desde la perspectiva de la seguridad. Por un lado, se defiende la postura en la que se deben aunar esfuerzos para reconocer, defender y garantizar los derechos civiles y humanos de los migrantes, y por el otro, pero desde la misma óptica se mira a estos individuos como causa del incremento de la inseguridad nacional, fronteriza e internacional y como fuente de desestabilización regional. De ahí que en muchos Estados, para los organismos de seguridad fronteriza o interna, el inmigrante es sujeto de control no sólo por lo que es en la actualidad, sino por lo que potencialmente puede ser. 
El objetivo de este ensayo es demostrar que a pesar de los acuerdos y resoluciones existentes, que pretenden regular la migración en la Región Andina como tema de la agenda común privilegiando los derechos de los emigrantes, no se ha podido concretar debido a factores políticos como también factores sistémicos. Para lograr este objetivo, se revisará en primer lugar, la migración, la globalización y la manera como la primera se ha convertido en un reto de la segunda, en segundo lugar se mirarán las concepciones de seguridad en la Región Andina, en tercer lugar la securitización de las migraciones, como cuarto punto los antecedentes y contexto actual de los procesos de integración, además las políticas de movilidad migratoria, sus perspectivas y proyección; para finalmente concluir que es difícil o casi imposible compatibilizar y tener un diálogo amplio y articulado en torno a las migraciones internacionales, debido al bajo nivel de responsabilidad recíproca en la gobernanza y la relación de los países con la migración.

\section{LA MIGRACIÓN Y LA GLOBALIZACIÓN}

En el estudio de las migraciones, es imprescindible tener en cuenta el proceso de globalización, que si bien maneja un discurso incluyente ha extendido considerablemente las brechas entre pobres y ricos en el Sistema Internacional, lo que ha incrementado los movimientos poblacionales.

En ese contexto, la crisis económica de la región se ha profundizado especialmente durante la última década, lo que se refleja en la caída del ritmo de crecimiento del producto industrial y la desarticulación y pérdida de dinamismo de la acción pública. Por tal razón, muchos habitantes de la región tienen problemas para insertarse con éxito en la dinámica económica de sus respectivos países, y por ende, acceder a unas condiciones mínimas de bienestar. Estas condiciones precarias los lleva a una opción, como emigrar hacia al exterior, sin el lleno de las formalidades$^{1}$, lo que los sitúa en estatus de irregularidad. En ese sentido, se puede afirmar que las personas migrantes de la región «están sometidas a una mayor tensión, producto de la aguda discrepancia entre los deseos de alcanzar la meta cultural del éxito económico y la menor disponibilidad de medios para alcanzarlo» (Romano y otros, 1969: 2).

En esa misma dirección, la estrategia de corte neoliberal y su respectiva implementación en la región ha recibido varias críticas, toda vez que según varias fuentes, este modelo económico ha empobrecido aún más la región y su inserción desventajosa en el sistema económico mundial².

\footnotetext{
${ }^{1}$ Cada Estado determina los requisitos para que un migrante pueda residir legalmente. Esta determinación forma parte de la soberanía estatal que es el poder absoluto sobre su territorio y que no está sometido a otro poder. Transgredir las normas de cada Estado en materia de migración conlleva a fenómenos de trafico ilícito de migrantes, residir irregularmente en el país de destino y ser, con facilidad, victima de trata de personas.
}

${ }^{2}$ Al respecto, véase: Ahumada, Consuelo, El modelo neoliberal, Ancora Editores, Bogotá, 1998 
Como consecuencia de lo anterior, los Estados andinos, en primer término, no han logrado brindar un mediano estado de bienestar a sus poblaciones respectivas, por tanto, la gente tiene que auto proveerse, de ahí que Cardona afirma que «La esperanza de mejorar su vida por parte del migrante constituye la causa fundamental de la migración $»^{3}$ (Cardona y Simmons, 1978: 6). Otra consecuencia ha sido el aumento de la oleada migratoria. En el anexo 1 y 2 se encuentran las estadísticas del Departamento Administrativo de Seguridad -DAS de Colombia de movimientos migratorios en la región andina. El 1 presenta entradas y salidas por nacionalidad y años y el 2 contiene las estadísticas correspondientes a entradas y salidas de colombianos por procedencia y destino. Esto da un panorama del aumento que se ha dado en las migraciones registradas intracomunitariamente.

El fenómeno migratorio se fortalece en y con la globalización, por eso, en los diversos Estados, se plantea como prioridad de la agenda nacional garantizar la seguridad y potenciar el desarroIlo. Además, «la migración se ha identificado como consecuencia de los cambios producidos por ese fenómeno, ligado a la importancia cada vez menor de las fronteras, la tendencia a la eliminación de las mismas y la formación de comunidades transnacionales» ${ }^{4}$.

Este proceso, junto a la relativización de las fronteras y los cambios que esto conlleva, implica grandes desafíos en términos de fortalecimiento de la seguridad tanto nacional como ciudadana. Es innegable que la migración crea comunidades que rebasan las fronteras territoriales. Esta eliminación de las fronteras avanza paralelamente a las nuevas fronteras sociales y culturales creadas dentro del Estado. Al mismo tiempo, estas comunidades transnacionales debilitan la función de territorialidad de las identidades nacionales, entrando con ello a cuestionarlas.

En este documento hay que destacar el comportamiento de las unidades que conforman la comunidad Andina en el tema migratorio, desde la óptica de la globalización. A pesar que el fenómeno migratorio no es nuevo, si hay cambios y nuevas tendencias migratorias. Los cambios se reflejan en las razones de la migración como la aventura, por razones de retiro laboral y los destinos elegidos. Así «Siempre se ha identificado como los principales países receptores a los desarrollados, sin embargo, como afirma Cristina Blanco esto «\{...\} puede inducir a error $»^{5}$.

Las migraciones intracomunitarias de la región andina han tenido un especial incremento, esto se debe por una parte a la dolarización del Ecuador y por la sostenida migración transfronteriza

\footnotetext{
${ }^{3}$ Cardona y Simmons hace esa afirmación con base en los escritos de Ravenstein de la obra The Law of Migration.

${ }^{4}$ Cita de Graciano, Battistella. «Migraciones asiáticas y relaciones internacionales: perspectivas de futuro». Revista CIDOB d'Afers Internacionals, núm. 68, pp. 165-179.

${ }^{5}$ Blanco, Cristina. Migraciones. Nuevas movilidades en un mundo en movimiento. ANTHROPOS. Barcelona, España, 2006. p. 12
} 
de Colombia a Ecuador a causa de las confrontaciones entre las Fuerzas Armadas Colombianas y los grupos al margen de la ley. «Ecuador ha experimentado un incremento importante en el numero de solicitantes de refugio provenientes de Colombia» ${ }^{6}$.

La ausencia de cifras actualizadas sobre la migración intracomunitaria en la región andina es un enorme reto. Las cifras mas recientes con las que cuenta CELADE sobre estas dinámicas se remontan a los noventa ${ }^{7}$. Esto se convierte en un primer y gran reto.

Adicionalmente, no es un secreto que no hay identidad en el tratamiento del problema y mucho menos consenso a la hora plantear políticas vinculantes que garanticen los derechos humanos y civiles de los migrantes en la subregión. Al contrario, el proceso globalizador profundiza los caminos divergentes en el tratamiento del fenómeno migratorio, en tanto que las prioridades de los Estados son diferentes. Por ejemplo, Bolivia está concentrada en los problemas que sus emigrantes causan a sus vecinos del sur de la región, porque uno de los destinos preferidos de los bolivianos, entre otros, es la Argentina. Por otro lado, Ecuador cuyos bajos niveles de calidad de vida se constituyen en un factor expulsor, hacen de la migración parte de la cultura y una forma de conseguir un mejor modus vivendi. Legendariamente, Colombia ha mantenido una posición cerrada hacia la inmigración, por tanto, se ha caracterizado por políticas migratorias restrictivas, que no se compaginan con la aspiración regional.

Entonces, no sólo la falta de identidad en la región para tratar el problema de las migraciones sino la globalización restringe el proceso natural de movilidad y migración internacional al imponer normas que dificultan y limitan la libre circulación de personas. En este contexto se privilegian los conceptos y principios de seguridad estatal sobre los derechos humanos.

También, la globalización ha dado paso a dinámicas distintas como el fenómeno de la feminización de los movimientos migratorios debido a que se ha centrado el estudio en los movimientos del género masculino. Las estadísticas de los flujos migratorios en la región andina demuestran que ha aumentado considerablemente la migración de las mujeres por ser éstas, en muchos casos, cabeza de familia, por ser blanco de persecuciones políticas, y por casos de violencia intrafamiliar. «Esta situación se ha visto reforzada, por una gran ausencia, hasta épocas muy recientes, de las mujeres en

\footnotetext{
${ }^{6}$ Plataforma Interamericana de Derechos Humanos, Democracia y Desarrollo. Migraciones en America Latina y el Caribe: magnitud, volumen y tendencias En: Migraciones y Derechos Humanos, Primer informe para la Consulta Permanente sobre Migraciones y Derechos Humanos en America Latina y el Caribe. Ediciones Antripos, Bogota, Colombia, abril 2008. p. 27

7 Para ver la información al respecto revisar: Un examen de la migración internacional en la Comunidad Andina. Reseña del documento CEPAL-CELADE-OIM, Proyecto SIMICA En: http://www.eclac.cl/publicaciones/xml/6/6136/ LCG2058-rese00e.html
} 
el espacio publico, debido fundamentalmente, a su considerado menor estatus y a sus roles asignados en la esfera privada-reproductiva, que no ha empezado a cambiar hasta fechas muy recientes y a un ritmo mucho mas lento de lo que, al menos una buena parte de esta sociedad desearía ${ }^{8}$

En este sentido, es importante anotar que «La migración intrarregional en América Latina y el Caribe presenta, además del crecimiento de su magnitud absoluta, especificidades cualitativas que adelantan un examen de las consecuencias de los procesos migratorios: la feminización de los flujos, una mayor concentración en zonas urbanas, el aumento de la migración de personal calificado entre los países, y las menores incidencias en el grado de carencias habitacionales entre los extranjeros nacidos en la región, en contraste con las personas nativas de los países de destino. Estas características seleccionadas, permiten profundizar en los significados económicos y sociales de la migración intrarregional» (CEPAL, 2006, 87)

\section{SEGURIDAD: CONCEPCIONES DE SEGURIDAD EN LA REGIÓN ANDINA}

La Seguridad Nacional y los Derechos Humanos han sido temas tradicionalmente conflictivos. La emergencia mundial de la promoción de los Derechos Humanos desde la mitad del siglo XX se ha visto como una contradicción de los principios fundamentales de la seguridad nacional, muchas veces promoverlos ha sido vista como un lujo o una opción, que los gobiernos pueden tomar cuando las condiciones políticas y diplomáticas se lo permiten.

La securitización de las agendas de política exterior post 11 de Septiembre ha cambiado la mirada hacia los migrantes; se les identifica como factor de incremento de inseguridad nacional y desestabilización regional, lo que ha permitido que medidas restrictivas y sanciones, sean incluidas en legislaciones nacionales.

Sin embargo, parecería que bajo un nuevo concepto de seguridad se tienen en cuenta no solamente los aspectos de integridad territorial y soberanía desde una clásica concepción Westfaliana, sino una serie de elementos que contribuyen a fortalecer la seguridad y no tienen que ver con elementos tradicionales de política de seguridad del Estado, alimentación, pobreza, desarrollo y medio ambiente son elementos que han enriquecido la discusión sobre el tema de Derechos Humanos y Seguridad Estatal.

En la Conferencia Especial sobre Seguridad de la OEA celebrada en México en Octubre de 2003, la Declaración sobre Seguridad en las Américas ${ }^{9}$, define la nueva concepción de la seguridad en

\footnotetext{
${ }^{8}$ VICENTE. Trinidad. Importancia de los flujos migratorios de mujeres. Universidad de Deusto en: Migraciones. Nuevas movilidades en un mundo en movimiento. ANTHROPOS. Barcelona, España, 2006. p. 206

${ }^{9}$ http://www.oas.org/documents/spa/DeclaracionSecurity 102803.asp. Consultada en julio de 2007
} 
el hemisferio como «de alcance multidimensional, incluye amenazas tradicionales y nuevas amenazas, preocupaciones y otros desafíos a la seguridad de los Estados del Hemisferio, incorpora las prioridades de cada Estado, contribuye a la consolidación de la paz, al desarrollo integral y a la justicia social y se basa en valores democráticos, el respeto, la promoción y defensa de los derechos humanos, la solidaridad, la cooperación y el respeto a la soberanía nacional». Como podemos ver esta nueva concepción da especial importancia al respeto de los Derechos Humanos y la democracia.

La XV Cumbre Presidencial Andina de la CAN realizada en Quito en Julio de 2004, aprobó por primera vez unos Lineamientos de Política de Seguridad Común ${ }^{10}$, basados en una nueva concepción de seguridad, fundamentada en el respeto a la democracia, la cooperación entre Estados y la no agresión, propendiendo por la reducción de los gastos militares, además de establecer la Zona de Paz Andina que hará, de la Subregión, un territorio libre de armas de destrucción masiva y brindará a la Comunidad Andina una herramienta para consolidar el mantenimiento de la paz y la convivencia pacífica entre los pueblos andinos, articulándose a una zona de paz sudamericana ${ }^{11}$.

Aun cuando los países de la Región Andina, manejan conceptos de «seguridad» basadas en directrices universales y hemisféricas, cada uno de ellos ha construido para sí su propia forma de entender este término, la cual influye en la perspectiva que manejen sobre las dinámicas migratorias, haciéndose manifiesta en diferentes documentos oficiales.

De acuerdo al concepto ampliado de seguridad que se está manejando actualmente no sólo a nivel académico, sino por los hombres/mujeres de Estado, en el que se identifica amenazas no tradicionales para los Estados, la migración es considerada como una de ellas ${ }^{12}$. Por tanto, en este documento se recogerán las definiciones que los Estados andinos tienen de seguridad, para mirar si es posible articular una política migratoria acorde a los significados que tiene para cada uno de ellos o contrariamente, evitan que se avance significativamente en la integración, o más aún en materia de seguridad y lo que nos ocupa la migración, porque no exista unidad de criterio en definirlo y en esa misma dirección identificar amenazas comunes.

De esta forma, para Bolivia ${ }^{13}$ la Seguridad Interna está ligada estrechamente a las amenazas que pueden obstaculizar el desarrollo, entre las que se encuentran la corrupción, la delincuencia, la

\footnotetext{
${ }^{10}$ http://www.comunidadandina.org/normativa/dec/D587.htm. Consultada en julio de 2007

${ }^{11}$ http://www.comunidadandina.org/cumbre quito/np12-7-04b.htm. Consultada en julio de 2007

${ }^{12}$ LARA. Ana Maria. Perspectivas de Seguridad de las Migraciones Internacionales: Una propuesta para enfrentarlas. En: Revista de Relaciones Internacionales, Estrategia y Seguridad. Vol. 3 No. 1 Enero - Junio. P. 149 -174

${ }^{13}$ Información al respecto se encuentra en: http://www.resdal.org/atlas/atlas-definiciones-a.html. Consultada en agosto de 2007
} 
inestabilidad política, el tráfico de armas, el narcotráfico y el terrorismo. De otro lado, considera la Seguridad Externa como un elemento relacionado con la independencia nacional, la integridad territorial y la soberanía nacional, y su garantía es responsabilidad tanto de los órganos de defensa nacional, como de los canales de la diplomacia.

Para el caso de Ecuador ${ }^{14}$, en el entendido de que la Seguridad Nacional es responsabilidad del Estado, éste deberá garantizar la supervivencia de la colectividad, la defensa del patrimonio nacional y la consecución y mantenimiento de los objetivos nacionales, fortaleciendo la unidad nacional, asegurando el respeto de los derechos fundamentales de hombre y promoviendo el progreso económico, social y cultural de sus habitantes. Para esto, se deberán contrarrestar los factores adversos internos y externos, por medio de acciones políticas, económicas, sociales y militares. Ahora bien, en el marco del Plan Ecuador ${ }^{15}$, el gobierno de ese país establece que la Defensa Nacional responde a los objetivos de la Seguridad Nacional, para el mantenimiento de la soberanía y la protección de la población, las fronteras y los recursos naturales, pero dentro el objetivo claro de garantizar la convivencia pacífica de las naciones.

Perú ${ }^{16}$ comprende la Seguridad Nacional como la situación en la cual el Estado tiene garantizada su independencia, soberanía e integridad y, la población, sus derechos fundamentales establecidos en la Constitución; en este sentido, la Defensa Nacional estaría determinada por el conjunto de medidas, previsiones y acciones que el Estado genera, adopta y ejecuta en forma integral y permanente, tanto en el ámbito interno como en el externo.

Finalmente, para Colombia ${ }^{17}$, la Seguridad se entiende como la protección del ciudadano y de la democracia por parte del Estado, con la cooperación solidaria y el compromiso de toda la sociedad. En ese sentido, la Seguridad Democrática se fundamenta en tres pilares: la protección de los derechos de todos los ciudadanos, la protección de los valores, la pluralidad y las instituciones democráticas, y la solidaridad y la cooperación de toda la ciudadanía en defensa de los valores democráticos, el objetivo central entonces, es reforzar y garantizar el Estado de derechos en todo el territorio, mediante el fortalecimiento de la autoridad democrática, el imperio de la ley y la participación activa de los ciudadanos en los asuntos de intereses común.

\footnotetext{
${ }^{14}$ Ley de Seguridad Nacional No. 275-09/08/79, Art 1 y 2

${ }^{15}$ Véase documento general en Página Web: http://www.mmrree.gov.ec/mre/documentos/ministerio/planex/ PLANEX 2020.pdf Consultado 7 de noviembre de 2007

${ }^{16}$ Información al respecto se encuentra en: http://www.resdal.org/atlas/atlas-definiciones-a.html. Consultada en agosto de 2007

17 Véase texto completo en alpha.mindefensa.gov.co/dayTemplates/images/seguridad democratica.pdf
} 


\section{SECURITIZACIÓN DE LAS MIGRACIONES ¿EN QUÉ QUEDA LA MOVILIDAD?}

En este sentido, y siguiendo la tendencia general, en los países Andinos, los migrantes en su mayoría son vistos como una amenaza para la seguridad de los diferentes Estados porque los actos de violencia perpetrados por migrantes y miembros de grupos minoritarios y los vínculos de estos con actividades delictivas ${ }^{18}$, han creado la opinión de que existe un vínculo estrecho entre migraciones y terrorismo internacional ${ }^{19}$. Además, los países receptores de la región no cuentan con la infraestructura social suficiente para recibir a los que llegan, lo que genera inseguridad nacional porque los migrantes no pueden autoabastecerse con el fruto de un trabajo digno y se involucran muchas veces en actos vandálicos.

Los diferentes análisis y posturas que se dan en las esferas públicas de los diferentes países en torno a mantener actitudes para responder a las migraciones internacionales cuestionan la formulación de las políticas públicas migratorias desde la securitización. Una tendencia en la que se mantiene la seguridad nacional como factor de militarización de la política migratoria en los planos internacional y nacional. Se podría afirmar entonces que se están retomando los principios y bases de la Doctrina de Seguridad Nacional (DSN), en contra de todos aquellos países mayormente expulsores de migrantes; así, la respuesta de militarización de las fronteras por parte de los países vecinos de Colombia, y de la percepción de amenaza que se maneja de la migración colombiana es la prueba fehaciente que muchos mantienen vigente esta Doctrina que en los años 70 se aplicó con tanto rigor en países de América Latina.

El aumento de la migración transfronteriza en la Región, no solamente ha generado la implementación de políticas tendientes a mejorar el desarrollo de las naciones, a causa de mandatos internacionales, sino que adicionalmente ha incrementado el grado de militarización propio de los principios de la DSN y políticas migratorias cada vez más restrictivas. Sin embargo, y a pesar de lo esperado con la aplicación de estas estrategias, el número de migrantes no ha disminuido, al contrario, ha crecido ${ }^{20}$, haciendo proclive la asociación de «migraciones» con «seguridad». Dicho fenómeno se ha generalizado afectando hoy en día a países del norte, pero

\footnotetext{
${ }^{18}$ Lara. Ana Maria. «Migraciones internacionales, seguridad y xenofobia: los límites del modelo francés de integración», en Oasis 2006-07, núm. 12, Centro de Investigaciones y Proyectos Especiales, CIPE, Facultad de Finanzas, Gobierno y Relaciones Internacionales. Universidad Externado de Colombia, pp. 209-227.

${ }^{19} \mathrm{El}$ informe de la Comisión mundial sobre las migraciones internacionales señala que «las migraciones irregulares, que en muchas partes del mundo están aumentando, son consideradas por los políticos y el público como una amenaza para la soberanía y la seguridad del Estado. En toda una serie de países de destino, las sociedades anfitrionas temen cada vez más la presencia de comunidades migrantes, en particular aquellas con culturas desconocidas y procedentes de regiones del mundo asociadas con el extremismo y la violencia». En: http:// www.gcim.org/mm/File/Spanish.pdf. Consultada en julio de 2008

${ }^{20}$ Weiner, Mayron, «Security and International Migration», en International Security, No. 17(3), pp. 91-126.
} 
también países del sur ante el incremento que ha tenido la migración intraregional. Adicionalmente son cada día más países que por ser de origen o recepción se están viendo afectados por las dinámicas migratorias, convirtiendo el tema en una prioridad en la agenda internacional ${ }^{21}$. En esta lógica, diferentes intelectuales intentaron incluir la migración en el estudio de las relaciones internacionales. Una de las más notables contribuciones en este aspecto, fue el trabajo de Myron Weiner (1992) que planteó la idea que en el ámbito de las relaciones internacionales el análisis de la migración internacional suele relegarse al campo de lo que se denomina «low politics» o un asunto concerniente a la política interna de las naciones, y solo incidentalmente ocupa el centro de atención de la política internacional o «high politics» cuando el tema se convierte en un tema candente, particularmente cuando existe una «crisis» política internacional.

Es así, que sobre los Estados recae la responsabilidad de formular políticas públicas; en esa tarea confluyen las presiones de los diferentes actores sociales, ya sea en forma directa o a través de la opinión pública, para la adopción de determinada política migratoria ${ }^{22}$, la cual, según Lelio Mármora, se ve muy influenciada por el imaginario colectivo tanto de la sociedad de origen como de la de destino. En ese sentido, es importante tener en cuenta que más allá de la percepción y del papel del Estado, la sociedad nacional e internacional, en general, desempeñan un papel determinante en la conformación de dicho imaginario. De esta forma, los grupos de presión y la opinión pública pueden hacer que la imagen del migrante sea negativa o positiva en función de sus intereses, es decir, ya sea a través de los medios de comunicación o del análisis de opinión, la percepción que se transmite puede generar o reforzar las imágenes que tengan los actores sociales y, de esta forma, ejercer presión al Estado. Como señala Mármora (2002), «en los medios de comunicación la percepción del migrante puede conformarse, ya sea respondiendo a determinados intereses sectoriales, representando posiciones principistas frente a la migración, o bien, buscando la noticia más vendedora en el tema $\{\ldots\}$ el medio de comunicación se dedica a explotar aquellos aspectos de la «noticia migratoria» que puedan tener mayor impacto no importa lo positiva o negativa».

Esas noticias inciden en la forma como es percibida, recibida y aceptada la población migrante, pero por lo general incitan y alimentan la xenofobia. La intolerancia y el no respeto a las diferencias, atentan no sólo, contra la dignidad y la libertad del ser humano, sino que aumenta

\footnotetext{
${ }^{21}$ Más información al respecto en Graciano, Battistella. «Migraciones asiáticas y relaciones internacionales: perspectivas de futuro». Revista CIDOB d'Afers Internacionals, núm. 68, pp. 165-179., 2005

${ }^{22}$ Los diferentes actores de la sociedad elaboran una imagen de las migraciones de acuerdo a la percepción que tienen sobre sus características, causas y efectos. En este sentido como Mármora $(2002,54)$ plantea existe una «distancia perceptiva» existente entre el hecho objetivo y el imaginario colectivo que puede llegar a ser muy grande, distorsionando no sólo las actitudes de vastos sectores sociales, sino también las políticas aplicadas por los Estados
} 
significativamente las percepciones negativas acerca de los inmigrantes, ya sean regulares o irregulares ${ }^{23}$.

La llegada de inmigrantes cuestiona los estereotipos nacionales y genera en muchos casos crisis de identidad en las comunidades transnacionales. Vistas las cosas en perspectiva psico-social ${ }^{24}$ y desde el lado de los inmigrantes, la mayor dificultad con la que ellos tropiezan para su plena integración es el conjunto de estereotipos denigrantes, adversos o, al menos, inadecuados, a través de los cuales se les mira y se les trata. Si bien es cierto, muchos de estos estereotipos, son resultado del accionar de migrantes al margen de la ley, la verdad es que la mayoría no se dedican a la delincuencia y sin embargo, son estigmatizados como tal.

«Estos estereotipos, incluso cuando no incluyen rasgos racistas o xenófobos, proyectan sobre ellos imágenes generalizadas que impiden verles tal como son en su realidad personal. Se tiende, por tanto, a poner en crisis su autoestima y, más allá de ella, la autoconfianza con que pueden manejar las situaciones de su vida diaria y la idea de sí mismos con que se manejaban previamente a su venida. Muchos experimentan una verdadera «crisis de identidad», pero la gran mayoría, sin llegar a ello, se ve en la necesidad de aprender a mirarse con los ojos de sus interlocutores y a reconciliar la imagen que tienen de sí mismos con la máscara de «inmigrante de tal nacionalidad», que les reviste ante sus interlocutores» ${ }^{25}$.

La antipatía hacia los extranjeros, consecuencia de imágenes prejuiciosas, hace ver al inmigrante como la causa de los males de la sociedad, como el enemigo social contra el que hay que luchar y justificar respuestas xenofóbicas. Se hacen por lo tanto juicios espontáneos sobre lo «extraño» o lo que se considera «el enemigo» al cual se le pueden atribuir los problemas de la nación. Así, se contempla el hecho que una sociedad se puede ver perturbada por una eventual formación en su seno de minorías cívicamente marginadas, productos de las inmigraciones. Tales minorías se convierten en fuentes de conflictividad y de peligrosidad social que deterioran la calidad de la común convivencia que amenaza la seguridad.

\footnotetext{
${ }^{23}$ A pesar de que se ha debatido el tema en foros multilaterales de los que han emanado documentos que rechazan cualquier forma de discriminación como la Declaración y el Programa de Acción de Durban, Sudáfrica, realizada entre el 31 de agosto y el 8 de septiembre de 2001, entre otros, en los que recomiendan a los propios Estados y a las organizaciones internacionales hacer campañas para promover respeto por la multiculturalidad y en algunas ocasiones rechazar cualquier conducta xenófila, los resultados son escasos en la medida que los receptores ven a los recién llegados como los que usurpan las pocas oportunidades.

${ }^{24}$ Para más información sobre la perspectiva psico-social aplicada, véase Campbell, Angus, The American Voter. Midway Reprint. The University of Chicago Press. Chicago and London. 1980.

${ }^{25}$ Labrador Fernández, Jesús. presentación del curso Crisis de identidad y reconstrucción de la identidad entre los inmigrantes en:

http://www3.upco.es/pagnew/iem/nueva/03formacion/doctorado/CURSOS\%20FUNDAMENTALES.doc
} 
Un factor a considerar es el discurso nacionalista de diferentes países, que brota con más fuerza en contra de la población inmigrante toda vez que se le ve como una amenaza para los valores tradicionales, ${ }^{26}$ y se les culpa de acabar con los recursos escasos existentes a los que sólo tienen y deben tener derecho los nacionales desde la vista del común. Es por ello, que generalmente, a los migrantes en el mejor de los casos, se le ofrecen trabajos que tienen peores condiciones de salario, esfuerzo físico, etc., ya que los trabajadores del país receptor tienen prioridad para escoger los mejores empleos y con mejores condiciones (Recio, 2002: 30), lo que genera discriminación y rechazo.

Analizar el problema de la xenofobia entonces, requiere una mirada amplia y minuciosa ya que persisten los casos violentos de racismo, discriminación racial, xenofobia y se sigue fomentando las teorías de la superioridad de ciertas razas como en épocas coloniales. (Oficina en Colombia del Alto Comisionado de la Naciones Unidas para los Derechos Humanos. Declaración y el Programa de Acción de Durban, conferencia Mundial contra el Racismo, la Discriminación Racial, la Xenofobia y las formas conexas de Intolerancia, 2002: 13)

\section{ANTECEDENTES Y CONTEXTO ACTUAL DE LOS PROCESOS DE INTEGRACIÓN}

En el continente Americano existen actualmente cuatro grupos de integración subregional diseccionados a la conformación de Mercados Comunes: Mercado Común del Sur (MERCOSUR), la Comunidad Andina de Naciones (CAN), el Mercado Común Centroamericano (MCC) y la Comunidad del Caribe (CARICOM). De estos ejercicios de integración y conformación de un mercado común, por la importancia que tiene para Colombia nos centraremos en la Comunidad Andina de Naciones, CAN. Originalmente conformada por Bolivia, Colombia, Chile, Ecuador y Perú; Venezuela adhirió en 1973 y Chile se retiró en 1976.

Los objetivos fijados dentro de este grupo son los de «promover el desarrollo equilibrado y armónico de los países miembros en condiciones de equidad, mediante la integración y la cooperación económica y social, acelerar su crecimiento y la generación de la ocupación y facilitar su participación en el proceso de integración regional (...) el 5 de septiembre de 1995 (Protocolo de Trujillo ), se efectuó un cambio importante en la estructura institucional del Acuerdo de Cartagena: se crea la denominación Comunidad Andina y se instituye el Sistema Andino de Integración conformado por varios organismos e instituciones. Los países asumieron el compro-

${ }^{26}$ Este fenómeno varía de un Estado a otro según su historia, cultura e idiosincrasia. 
miso de establecer, a más tardar en el 2005, un Mercado Común, fase superior de la integración que -como se ha dicho- se caracteriza por la libre circulación de bienes, servicios, capitales y personas $\aleph^{27}$. A pesar de los diferentes avance ${ }^{28}$ que se han tenido para llegar progresivamente a la meta, y de las diferentes disposiciones que se han adaptado en términos de libre circulación de bienes, servicios, capitales y personas, está claro que falta mucho camino para lograr la libre movilidad de las personas.

Se le suma, a las dificultades de llevar el proceso a su meta, los retos que han impuesto los resultados de los procesos electorales en los países de la región y las diferencias políticas que se han creado entre países vecinos, como el caso de la República Bolivariana de Venezuela, que decidió retirarse la comunidad.

«Es necesario asumir la integración como un proyecto político estratégico que pueda proyectar una presencia más sólida y competitiva no sólo de la región andina sino de América Latina en el mundo. La declaración final de la II Cumbre Sudamericana realizada en Cochabamba los días 8 y 9 de diciembre de 2006, menciona la necesidad de profundizar la integración a través del diálogo político que, a su vez, permita fortalecer un desarrollo más equitativo e integral basándose en ciertos principios rectores como la solidaridad, la búsqueda de la equidad, la superación de asimetrías y el respeto a la integridad territorial y autodeterminación de los pueblos» ${ }^{29}$.

Es evidente que la consolidación de los procesos de integración ha entrado en una etapa de estancamiento y flaqueo, razón por la cual se han empezado explorar mecanismos

\footnotetext{
${ }^{27}$ José Furiati M. Profesor UCLA. Diputado venezolano al Parlamento Latinoamericano., Situación actual y futuro de la Integración Latinoamericana, http://www.ucla.edu.ve/dac/investigaci\%F3n/compendium7/Integracion.htm. Consultada en enero de 2008

${ }^{28}$ «Desde el 1 de febrero de 1993 entra en funcionamiento una Zona de Libre Comercio entre Bolivia, Colombia, Ecuador y Venezuela, a lo cual se adhirió Perú el $1^{\circ}$ de agosto de 1997; zona que comprende todo el universo arancelario. Además, la adopción y aplicación a partir de febrero 1995, de un Arancel Externo Común para las importaciones provenientes de terceros países ha permitido la configuración de la Unión Aduanera Andina, que representa la etapa superior de la integración. Vale agregar que la evolución del comercio intercomunitario durante la pasada década fue de gran importancia, pues se cuadriplicó entre 1990 y 1998, destacándose que el 90\% del comercio intrandino está compuesto por productos manufacturados. La difícil coyuntura económica experimentada entre 1999 y 2000, ha determinado que esa tendencia se debilitara, solo que el 2001 muestra nuevos signos de recuperación. Dígase finalmente que las exportaciones intracomunitarias subieron de \$2.234 millones en 1992 a $\$ 5.410$ millones en 1998, a una tasa de crecimiento promedio interanual de 16\%. Para 1999 se presenta la peor crisis del comercio de intercambio en 31 años de integración, pues solo alcanzó a 3.943 millones de dólares, un descenso del $27 \%$ respecto al año anterior». Ibid.

${ }^{29}$ Información al respecto en: www.cumbrecochabamba.bo. Consultada en agosto de 2007
} 
diplomáticos ${ }^{30}$ de trabajo intergubernamental para mejorar el clima de concertación y coordinación como forma de inserción global.

\section{POLÍTICAS DE MOVILIDAD MIGRATORIA: ¿QUÉ HAY EN MATERIA DE MIGRACIONES EN LA REGIÓN?}

\section{Perspectivas y proyección}

Son muchos los avances que en materia de acuerdos y convenios se han establecido alrededor del tema de la libre circulación de personas no sólo en la comunidad andina sino en lo que a todos los países sudamericanos se refiere.

El marco que se ha venido estableciendo en los diferentes encuentros de la Conferencia Sudamericana sobre Migraciones ${ }^{31}$, en el que se han reunido los representantes de los Gobiernos de

\footnotetext{
${ }^{30}$ Tal como lo señala Francisco Rojas Aravena y Josette Altmann B en Multilateralismo e integración en América Latina y el Caribe». En primer lugar, en Latinoamérica como efecto de la globalización económica y acuerdos subregionales, las relaciones de interdependencia son cada vez más efectivas y vinculan las más diversas áreas, obligando a una más efectiva coordinación de políticas. En algunos casos se ha avanzado hacia una mayor coordinación en temas y áreas de la integración que le otorgan un carácter estratégico, generando una multitud de redes de interdependencia que pueden ser positivas, como aquellas que promueven la democracia, la complementación económica y el desarrollo; pero también las hay de carácter negativo que están emergiendo con fuerza, principalmente en relación con la criminalidad transnacional.
}

2. En segundo lugar, como se destaca en los Programas presidenciales de Chile, Perú, México, Honduras y Bolivia. principalmente en el marco sudamericano, se rompieron las hipótesis de amenaza militar derivadas de una geopolítica autoreferente. Las vinculaciones de cooperación a partir de la resolución de conflictos fronterizos y de mayor inserción en temas de seguridad internacional, ha cambiado referentes de la seguridad y defensa de los países mayores de esta subregión. 3. Y por último, la región se encuentra vinculada a través de una activa y densa red de conferencias, de una "Diplomacia de Cumbres» tanto de carácter hemisférica, regional, y extraregional; además de las Cumbres subregionales. En el ámbito de vinculación con España y Portugal los países latinoamericanos y caribeños han conformado un sistema de Cumbres Presidenciales, las Cumbres Iberoamericanas, de las que se han desarrollado diez y seis reuniones, desde 1990 fecha creación. En 2006 se realizó la reunión en Montevideo y para el año 2007 se llevará a cabo en Chile. A finales de 2004 se constituyó la Comunidad Sudamericana de Naciones que reúne a todos los países sudamericanos. Éstos acordaron establecer también un proceso de Cumbres Presidenciales Sudamericanas regulares como principal instrumento orientador del proceso, lo cual define a Sudamérica como un área geoestratégica con perfil propio. Las Cumbres han cumplido un importante rol en lo referido al diálogo político, pero con bajos niveles de articulación efectiva en términos de implementación y coordinación de políticas. Esto conlleva a suponer que dicho mecanismo podría estar pasando por un ciclo de agotamiento, debido a la falta de concreción de las iniciativas más relevantes que, a su vez, generan pérdida de energía y que erosionan la credibilidad y la legitimidad en ellas» .

${ }^{31}$ Las reuniones que se han sostenido han sido: Séptima Conferencia Sudamericana sobre Migraciones, realizada en Caracas, Republica Bolivariana de Venezuela 2007; sexta realizada en Montevideo, Republica Oriental del Uruguay 2006; Quinta celebrada en la ciudad de La Paz, República de Bolivia 2005; Cuarta en Montevideo 2003; Tercera en Quito 2002; Segunda en Santiago de Chile 2001; y la primera realizada en Buenos Aires, Argentina 2000; y Las diferentes conferencias se dieron en seguimiento del Encuentro Sudamericano sobre Migraciones, Integración y Desarrollo, en Lima de 1999. 
Argentina, Bolivia, Brasil, Colombia, Chile, Ecuador, Paraguay, Perú, Uruguay y Venezuela, lo que demuestra que existe amplia voluntad política de los países de la región para la gestión de los flujos migratorios.

Por ejemplo, en la Comunidad Andina, existen normas comunitarias y sus respectivas reglamentaciones, que tienen el propósito de ordenar el desplazamiento de los trabajadores migrantes andinos en el espacio comunitario (Decisión 545), sin menoscabo de sus derechos a la seguridad social (Decisión 583) y bajo condiciones adecuadas de seguridad y salud en el trabajo (Decisión 584).

Igualmente, en la Undécima Reunión del Consejo Andino de Ministros de Relaciones Exteriores de la Comunidad Andina, Ilevada a cabo en junio de 2003 se aprobó la Decisión 545 «Instrumento Andino de Migración Laboral», a través de la cual se adecua la normativa comunitaria al objetivo del Mercado Común y al derecho de los trabajadores andinos a desplazarse y establecerse libremente en el espacio comunitario.

En la actualidad, el Consejo Asesor de Ministros de Trabajo con el apoyo técnico de la Organización Internacional para las Migraciones (OIM), viene adelantando las bases del proyecto reglamentario de dicho Instrumento Andino.

\section{CONCLUSIONES}

Como se ha visto hasta ahora es casi imposible compatibilizar y tener un dialogo amplio y articulado en torno a las migraciones internacionales, la seguridad estatal y la integración subregional. En este sentido, darle prioridad al tema de la migración como un asunto de seguridad nacional, enfoque realista de las relaciones internacionales ${ }^{32}$, convierte a la movilidad en un asunto prioritario de la política exterior de los países, que se debe compatibilizar con las negociaciones comerciales.

Si bien es cierto, los países de origen no pueden determinar las políticas migratorias de otros países si puede hacer «diplomacia migratoria». Esto hace referencia a involucrar en negociaciones

\footnotetext{
${ }^{32}$ En este sentido se le da prioridad al Estado soberano sin descartar intereses nacionales en los objetivos y forma de conducción de las relaciones exteriores. Esta posición ha sido criticada por los internacionalistas que argumentan que la transformación generada por la progresiva integración de economías y cambios en la comunicación ha relegado el papel del Estado a una posición más marginal. Si bien algunos anunciaron el fin del Estado-nación, la mayoría coincidió en la importancia de las relaciones económicas y el establecimiento de relaciones transnacionales que requieren la participación de diferentes actores en las negociaciones, como las organizaciones internacionales, las empresas transnacionales y la sociedad civil.
} 
económicas y políticas el tema migratorio, interviniendo para la garantía de mayores cuotas de migrantes, así como el respeto de sus derechos. Por ejemplo, se debe promover la contratación de trabajadores así como irrumpir en las negociaciones multilaterales, donde antes se había evitado. Por lo tanto, al planificar la agenda de reuniones internacionales, las delegaciones de los diferentes Estados deberán intentar introducir un debate sobre la protección de los migrantes.

No se puede olvidar que la gestión migratoria debe partir del diálogo y la cooperación entre países de recepción y los de origen, por esta razón es necesario introducir en espacios multilaterales la necesidad de un mayor nivel de responsabilidad recíproca en la gobernanza y la relación de los países con la migración. Entonces, los países de recepción deben comprometerse a prever las condiciones mínimas que garanticen el desarrollo total y digno de sus nacionales, para prevenir la migración, en particular la irregular y los procesos de aculturación y estigma del extranjero.

Paralelo a la diplomacia migratoria, para el caso colombiano, el gobierno debe fortalecer los lazos con las comunidades de nacionales en transnacionales y promover planes de desarrollo que incorporen a estas comunidades. Estas comunidades, a su vez, serán fundamentales en la proyección y cambio de imagen de los colombianos en los países de recepción.

La tarea no es fácil. La necesidad de persistir en foros internacionales en quitarle la connotación negativa a la migración internacional, permitirá que los vínculos entre políticas migratorias y seguridad sean cada vez menores.

En esta tarea, los Estados, el sector productivo y la sociedad civil desarrollan un papel importante.»La condición migratoria genera una vulnerabilidad especifica, que requiere de medidas afirmativas de protección en las forma mas integral posible y que lleva a las institucionales nacionales de Derechos Humanos a generar acciones propias y especificas para abordar esta vulnerabilidad ${ }^{33}$ Aportar un grano de arena, para sacar avante el proyecto migratorio en la subregión como motor de desarrollo especialmente en aquellas zonas de donde salen mayor cantidad de emigrantes y aqueIlos destinos donde tratan de insertarse es indispensable. Este consenso demanda la formulación de política pública de todos los países ante un hecho que es real e inevitable, en que la evidencia empírica indica que a corto y mediano plazo va a seguir creciendo y que tutelar los derechos humanos en general, es un compromiso de la comunidad internacional.

Así, la formulación y ejecución de una política pública coordinada con los países de la subregión se justifica en la medida que las cifras de los migrantes aumentan vertiginosamente entre los miembros. Además, una postura subregional acerca del tema migratorio en la que se privilegie

\footnotetext{
${ }^{33}$ CARRASCO, Diego. Informe Mundial de Buenas Practicas en migración e instituciones nacionales de derechos humanos. Observatorio Internacional de Migraciones. Enero 2008. p. 5
} 
los derechos humanos, arrojaría dividendos no sólo regionales, sino, posicionaría a la región más allá y se podría negociar en conjunto, para lograr respeto de la comunidad internacional en general.

\section{BIBLIOGRAFÍA}

BLANCO, Critina. Migraciones. Nuevas movilidades en un mundo en movimiento. ANTHROPOS. Barcelona, España, 2006. p. 12

CARDONA, Ramiro y SIMMONS, Alan. Destino la Metrópoli, un modelo general de las migraciones internas en América Latina. Corporación Centro Regional de población. Bogotá, Colombia. 1978

CARRASCO, Diego. Informe Mundial de Buenas Practicas en migración e instituciones nacionales de derechos humanos. Observatorio Internacional de Migraciones. Enero 2008. p. 5

COMISION ECONOMICA PARA AMERICA LATINA Y EL CARIBE - CEPAL. Cuatro temas centrales en torno a la Migración internacional, derechos humanos y desarrollo. 10 de marzo del 2006. En: http:// www.eclac.org/publicaciones/xml/2/24012/LCG2490.pdf

COMISION ECONOMICA PARA AMERICA LATINA Y EL CARIBE - CEPAL. Un examen de la migración internacional en la Comunidad Andina. Reseña del documento CEPAL-CELADE-OIM, Proyecto SIMICA. En: http://www.eclac.cl/publicaciones/xml/6/6136/LCG2058-rese00e.html

COMISION MUNDIAL SOBRE LAS MIGRACIONES INTERNACIONALES. Informe de la comisión mundial sobre las migraciones internacionales 2005. En: http://www.gcim.org/mm/File/Spanish.pdf

GRACIANO Battistella., «Migraciones asiáticas y relaciones internacionales: perspectivas de futuro». Revista CIDOB d'Afers Internacionals, núm. 68, pp. 165-179.

LABRADOR FERNÁNDEZ, Jesús. Presentación del curso Crisis de identidad y en construcción de la identidad entre los inmigrantes en: http://www3.upco.es/pagnew/iem/nueva/03formacion/doctorado/ CURSOS\%20FUNDAMENTALES.doc

LARA, Ana Maria. «Migraciones internacionales, seguridad y xenofobia: los límites del modelo francés de integración», en Oasis 2006-07, núm. 12, Centro de Investigaciones y Proyectos Especiales, CIPE, Facultad de Finanzas, Gobierno y Relaciones Internacionales. Universidad Externado de Colombia, pp. 209-227.

LARA. Ana Maria. Perspectivas de Seguridad de las Migraciones Internacionales: Una propuesta para enfrentarlas. En: Revista de Relaciones Internacionales, Estrategia y Seguridad. Vol. 3 No. 1 Enero - Junio. P. 149 -174 
MÁRMORA, Lelio, 2002. Las políticas de Migraciones Internacionales, Buenos Aires, OIM-PAIDÓS.

MATHIS Albert, JACOBSON David y LAPID Yosef en su libro Identitis, borders, orders, rethinking internacional relations theory. University of Minnesota Press. 2001.

OFICINA EN COLOMBIA DEL ALTO COMISIONADO DE LA NACIONES UNIDAS PARA LOS DERECHOS HUMANOS. Declaración y el Programa de Acción de Durban, conferencia Mundial contra el Racismo, la Discriminación Racial, la Xenofobia y las formas conexas de Intolerancia. Siglo XXI Impresores Ltda. Bogotá. 2002.

PRESIDENCIA DE LA REPUBLICA DE COLOMBIA, MINISTERIO DE DEFENSA NACIONAL. Política de Seguridad y Defensa Democrática 2003. En: http://alpha.mindefensa.gov.co/dayTemplates/images/ seguridad_democratica.pdf

RECIO, M. Eugenio. Origen, Significado y Resultados de los Flujos Migratorios Masivos por Motivos Económicos en el Mundo Actual. J.M. Bosch Editor. España. 2002

ROMANO, Margot y Otros. Clase obrera y Migraciones. Editorial del Instituto. Buenos Aires Argentina. 1969

VICENTE. Trinidad. Importancia de los flujos migratorios de mujeres. Universidad de Deusto en: Migraciones. Nuevas movilidades en un mundo en movimiento. ANTHROPOS. Barcelona, España, 2006. p. 206

VILLA Miguel y MARTINEZ Jorge. El Mapa Migratorio Internacional de América Latina y el Caribe: patrones, perfiles, repercusiones, e incertidumbres. Universidad Externado de Colombia. 2004

WAEVER, Ole, «Securitization and Desecuritization», en Ronnie D. Lipschutz (dir.), On Security, New York, Columbia University Press, 1995, pp 46 - 86 o Barry, Buzan, y Ole, Waever, Security: A New Framework for Analysis, Boulder/ Londres, Lynne Rienner Publisher, 1998

WEINER, Mayron, «Security and International Migration». International Security. No. 17(3). p.p. 169 
Anexo 1

Entradas y salidas por nacionalidad y años 1998 - 2008

\begin{tabular}{|c|c|c|c|c|c|}
\hline Nacionalidad & & Perú & Bolivia & Ecuador & Colombia \\
\hline \multirow[t]{2}{*}{1998} & Entradas & 20.723 & 3.437 & 45.852 & 933.564 \\
\hline & Salidas & 19.500 & 3.317 & 35.979 & 1.093 .147 \\
\hline \multirow[t]{2}{*}{1999} & Entradas & 20.462 & 2.818 & 39.256 & 873.506 \\
\hline & \begin{tabular}{|l} 
Salidas \\
\end{tabular} & 19.297 & 2.815 & 28.788 & 1.098 .354 \\
\hline \multirow[t]{2}{*}{2000} & Entradas & 22.049 & 2.725 & 48.930 & 952.459 \\
\hline & Salidas & 20.004 & 2.747 & 35.518 & 1.234 .775 \\
\hline \multirow[t]{2}{*}{2001} & Entradas & 23.889 & 3.013 & 59.476 & 1.098 .553 \\
\hline & Salidas & 21.868 & 2.972 & 47.815 & 1.381 .032 \\
\hline \multirow[t]{2}{*}{2002} & Entradas & 23.216 & 2.806 & 55.701 & 1.141 .656 \\
\hline & Salidas & 21.505 & 2.774 & 45.384 & 1.277 .210 \\
\hline \multirow[t]{2}{*}{2003} & Entradas & 25.732 & 3.258 & 64.431 & 1.060 .947 \\
\hline & Salidas & 24.107 & 3.195 & 51.389 & 1.177 .220 \\
\hline \multirow[t]{2}{*}{2004} & Entradas & 36.654 & 4.771 & 91.682 & 1.246 .621 \\
\hline & \begin{tabular}{|l|} 
Salidas \\
\end{tabular} & 32.276 & 4.673 & 76.088 & 1.405 .174 \\
\hline \multirow[t]{2}{*}{2005} & Entradas & 40.730 & 5.825 & 95.816 & 1.412 .076 \\
\hline & Salidas & 105 & 5.704 & 83.305 & 1.552 .891 \\
\hline \multirow[t]{2}{*}{2006} & Entradas & 47.750 & 4.666 & 100.226 & 1.589 .392 \\
\hline & Salidas & 44.775 & 4.575 & 87.180 & 1.767 .626 \\
\hline \multirow[t]{2}{*}{2007} & Entradas & 58.862 & 5.837 & 111.337 & 1.835 .360 \\
\hline & Salidas & 55.964 & 5.853 & 101.494 & 2.040 .829 \\
\hline \multirow{2}{*}{$\begin{array}{l}\text { Julio } 31 \mathrm{de} \\
2008\end{array}$} & Entradas & 40.590 & 3.537 & 57.363 & 1.138 .052 \\
\hline & Salidas & 37.933 & 3.459 & 53.454 & 1.288 .768 \\
\hline
\end{tabular}


Anexo 2

Entradas y salidas de colombianos por país de procedencia-destino 1998 -2008

\begin{tabular}{|c|c|c|c|c|}
\hline $\begin{array}{c}\text { Procedencia - } \\
\text { destino }\end{array}$ & & Perú & Bolivia & Ecuador \\
\hline \multirow[t]{2}{*}{1998} & Entradas & 27.197 & 4.788 & 39.566 \\
\hline & Salidas & 14.145 & 5.002 & 120.049 \\
\hline \multirow[t]{2}{*}{1999} & Entradas & 20.798 & 3.766 & 38.881 \\
\hline & Salidas & 14.937 & 3.752 & 124.544 \\
\hline \multirow[t]{2}{*}{2000} & Entradas & 16.504 & 3.563 & 51.422 \\
\hline & Salidas & 16.813 & 3.696 & 157.164 \\
\hline \multirow[t]{2}{*}{2001} & Entradas & 28.697 & 2.190 & 61.484 \\
\hline & Salidas & 28.698 & 2.242 & 146.412 \\
\hline \multirow[t]{2}{*}{2002} & Entradas & 28.594 & 3.196 & 71.863 \\
\hline & Salidas & 25.954 & 2.302 & 164.062 \\
\hline \multirow[t]{2}{*}{2003} & Entradas & 21.954 & 6.551 & 72.169 \\
\hline & Salidas & 23.459 & 5.751 & 163.477 \\
\hline \multirow[t]{2}{*}{2004} & Entradas & 33.813 & 6.083 & 88.003 \\
\hline & Salidas & 34.344 & 6.196 & 180.061 \\
\hline \multirow[t]{2}{*}{2005} & Entradas & 42.380 & 6.710 & 87.205 \\
\hline & Salidas & 40.730 & 5.605 & 174.686 \\
\hline \multirow[t]{2}{*}{2006} & Entradas & 54.992 & 2.133 & 91.388 \\
\hline & Salidas & 53.131 & 1.842 & 180.095 \\
\hline \multirow[t]{2}{*}{2007} & Entradas & 67.171 & 1.695 & 105.114 \\
\hline & Salidas & 48.888 & 4.109 & 196.951 \\
\hline \multirow[t]{2}{*}{ Julio 31 de 2008} & Entradas & 47.025 & 759 & 58.142 \\
\hline & Salidas & 34.045 & 2.471 & 112.670 \\
\hline
\end{tabular}

